\title{
Vertebral artery transposition for revascularization of the posterior circulation: a critical assessment of temporary and permanent complications and outcomes
}

\author{
Leonardo Rangel-Castilla, MD, M. Yashar S. Kalani, MD, PhD, Katherine Cronk, MD, PhD, \\ Joseph M. Zabramski, MD, Jonathan J. Russin, MD, and Robert F. Spetzler, MD
}

Division of Neurological Surgery, Barrow Neurological Institute, Saint Joseph's Hospital and Medical Center, Phoenix, Arizona

\begin{abstract}
OBJECT Despite advances in medical management and endovascular therapies, including the introduction of statins, antiplatelet agents, and drug-eluting stents, some patients experience medically refractory vertebrobasilar insufficiency and may benefit from robust surgical revascularization. The aim of this study was to evaluate such patients after surgical revascularization, emphasizing long-term outcomes and rates of complications.
\end{abstract}

METHODS The authors retrospectively identified 22 patients ( 5 women and 17 men) whose mean age was 69.1 years (range 48-81 years) who underwent revascularization of the posterior circulation via a proximal vertebral artery-carotid artery transposition between 2005 and 2013. The patients' conditions before surgery were clinically summarized, and long-term outcomes and complication rates after surgery were evaluated.

RESULTS All the patients were symptomatic before surgery although they received the best medical therapy as defined by their primary care physician. Presenting symptoms consisted of stroke, transient ischemic attacks (TIAs), and/or findings attributable to posterior circulation hypoperfusion. There were no deaths associated with revascularization surgery. The postoperative complication rate was $45.5 \%$, which included 3 cases of recurrent laryngeal nerve palsy, 1 case of thoracic duct injury, 2 cases of TIA, and 4 cases of Horner's syndrome. The thoracic duct injury was identified intraoperatively and ligated without sequelae, all the TIAs resolved within 24 hours of surgery, all 4 sympathetic plexus injuries resolved, and all but 1 of the recurrent laryngeal nerve palsies resolved, resulting in a $4.5 \%$ complication rate in a mean follow-up period of 8.8 months. All the patients had resolution of their presenting symptoms, and a single patient had symptomatic restenosis that required stenting and angioplasty, resulting in a restenosis rate of $4.5 \%$.

CONCLUSIONS Despite the optimization of medical therapies and lifestyle modifications, a select subset of patients with posterior vascular circulation insufficiency remains. In the authors' experience, vertebral artery-carotid artery transposition provides a surgical option with relatively low long-term complication and restenosis rates that are comparable or lower than those reported with endovascular treatment.

http://thejns.org/doi/abs/10.3171/2014.9.JNS14194

KEY WORDS vertebral artery; stenosis; occlusion; revascularization; vertebrocarotid transposition; vertebral artery-carotid artery transposition; vascular disorders

$\mathrm{P}$ OSTERIOR circulation infarction accounts for $25 \%-$ $30 \%$ of all ischemic infarcts. ${ }^{3}$ After the carotid bifurcation, the proximal vertebral artery (VA) is the most common site of stenosis of the feeding vessels to the brain..$^{15}$ Unlike the carotid bifurcation, stenosis of the proximal VA that exceeds $30 \%$ is significantly associated with infarction in the posterior circulation ${ }^{21}$ and large-vessel occlusive disease is implicated in 14\%-32\% of infarctions in the posterior circulation. ${ }^{3,4}$

Unlike the carotid circulation, for which the natural history of stenosis is well understood, the natural his- tory of vertebrobasilar insufficiency is less well known. Furthermore, the effect of novel agents, including antiplatelet agents and statins, on altering the natural history of these lesions is less well studied. Recent attempts at the use of stenting and/or angioplasty for these lesions has produced mixed results $1,8,26,27$ and significant rates of restenosis, ranging from $11 \%$ for drug-eluting stents to more than $30 \%$ for bare-metal stents.

Microsurgical revascularization of the proximal VA has been well described, but the majority of published series included small patient populations and short follow-up

ABBREVIATIONS CCA = common carotid artery; CTA = CT angiography; $C V A=$ cerebrovascular accident; ICG = indocyanine green; $T I A=$ transient ischemic attack; VA = vertebral artery.

SUBMITTED February 3, 2014. ACCEPTED September 9, 2014.

INCLUDE WHEN CITING Published online November 14, 2014; DOI: 10.3171/2014.9.JNS14194.

DISCLOSURE The authors report no conflict of interest concerning the materials or methods used in this study or the findings specified in this paper. 
durations. ${ }^{2,9,10,14,25}$ Microsurgical revascularization can be performed by proximal VA endarterectomy, ${ }^{5}$ VA-common carotid artery (CCA) transposition,,$^{2,10,14}$ and graft interposition techniques. ${ }^{9}$ Indeed, most reports of VA revascularization have described a combination of the aforementioned techniques for augmenting flow to the posterior circulation. We sought to evaluate the outcomes of patients with medically refractory vertebrobasilar insufficiency treated with VA-CCA transposition, emphasizing the longterm outcomes and rates of complications in this group.

\section{Methods}

\section{Patient Population}

A retrospective analysis from the prospective vascular database of the Barrow Neurological Institute was performed on patients who had VA-CCA transposition.

Between 2005 and 2013, we treated 22 patients with medically refractory vertebrobasilar insufficiency using VA-CCA transposition at the Barrow Neurological Institute (Table 1). A medically refractory condition was indicated if the patients had persistent symptoms attributable to posterior circulation ischemia despite an adequate trial of best medical therapy. There were 17 men (77\%) and 5 women $(23 \%)$ with an average age of 69.1 years (range 48-81 years). Their medical records, neurological examinations, and radiographic studies were reviewed retrospectively. The patients' pre- and postoperative neurological function was evaluated using modified Rankin Scale scores.

\section{Diagnostic Evaluation}

All the patients underwent digital subtraction angiography, CT angiography (CTA), or MR angiography (Figs. 1 and 2).

\section{Surgical Technique}

We have previously described our VA-CCA transposition technique (Videos 1 and 2). ${ }^{14}$

VIDEO 1. A 52-year-old man had a history of symptomatic VA stenosis. Imaging was significant for severe stenosis of the left VA at its origin. The patient was advised to undergo a left VA-CCA transposition. A 4-cm incision along the anterior border of the sternocleidomastoid muscle, beginning at the superior edge of the clavicle, is used for access. After exposing the left CCA just superior to the clavicle, the thoracic duct is dissected out, ligated, and divided. The VA is identified and traced as inferiorly as possible. The proximal VA is ligated and divided after heparinization, and the CCA is occluded and rotated to allow anastomosis to the posterior lateral wall. A running 6-0 Prolene suture is used to perform the anastomosis, which is then back-bled, and patency is confirmed with an intraoperative ICG angiogram. Copyright Barrow Neurological Institute. Published with permission. Click here to view with Media Player. Click here to view with Quicktime.

VIDEO 2. A 64-year-old woman had symptomatic VA stenosis. Imaging was significant for severe stenosis of the left VA at its origin. The patient underwent a left VA-CCA transposition. A 4.5$\mathrm{cm}$ incision along the anterior border of the sternocleidomastoid muscle, beginning at the superior edge of the clavicle, is used for access. After exposing the left CCA just superior to the clavicle, multiple thoracic ducts are dissected out, ligated, and divided. The VA is identified and traced as inferiorly as possible. Intraoperative ICG angiography demonstrated lack of blood flow to the VA. The proximal VA is cut without ligation to verify patency and blood flow.
The proximal portion of the VA is clamped. A Fogarty balloon is inserted into the distal VA, and a thrombectomy is performed until adequate backflow is obtained. Then the artery is irrigated and heparinized. The CCA is occluded and rotated to allow anastomosis to the posterior lateral wall. A running 6-0 Prolene suture is used to perform the anastomosis, which is then back-bled, and patency is confirmed with an intraoperative ICG angiogram. Copyright Barrow Neurological Institute. Published with permission. Click here to view with Media Player. Click here to view with Quicktime.

Surgery is performed under general anesthesia. Somatosensory evoked potential monitoring and electroencephalography are routinely used. Barbiturate-burst suppression is induced before vascular clamping and maintained during occlusion. The head is kept in a neutral position with no extension (to prevent stretching of the muscle). A 6- to 8-cm linear incision is made along the medial border of the sternocleidomastoid muscle. Both muscle heads are dissected and separated. (The clavicular head is no longer taken, as we used to do in the past.) Dissection is carried down until the CCA is identified and isolated. The jugular vein is identified and isolated. Special attention must be paid to the thoracic duct, especially on the left side. This pale vessellike structure should be identified on the fat pad deep to the jugular vein; it is ligated and divided. It is not uncommon to encounter more than 1 thoracic duct (Video 2).

The VA is identified using anatomical landmarks. The thyrocervical trunk originates from the subclavian artery and is visualized first. Medial to this trunk, the VA can be identified. The VA can be distinguished from the thyrocervical and costocervical trunks by the lack of branches on its proximal segment. The C- 6 transverse process can be palpated to guide identification and localization of this vessel. The CCA and VA are isolated and liberated from adhesions.

The CCA is the site most commonly used to implant the transposed VA. The initial step is to ligate the VA at its origin with hemoclips. The VA is divided, and the lumen is inspected. The VA is clamped with a temporary aneurysm clip at the level of the transverse foramen. The lumen is irrigated with heparinized saline. The CCA is clamped proximal and distal to the planned level of the arteriotomy. Using the vascular clamps, the CCA is rotated slightly to bring the back wall of the vessel up, facilitating the anastomosis and enabling it to be seated further posteriorly in a better anatomical position at the conclusion of the procedure.

Using a No. 11 blade followed by a 4-mm-diameter arteriotomy punch, the arteriotomy is performed. The vessel is fish-mouthed as needed to tailor it to the diameter of the CA arteriotomy. A 6-0 monofilament Prolene (Ethicon, Inc.) is used for the anastomosis. After one side is done, the lumen is inspected. The procedure is then performed on the second side.

Before the suture line is closed, the distal VA is temporarily unclamped and allowed to back-bleed. The lumen is irrigated with heparinized saline. All arterial clamps are released. Small bleeding points at the suture line are usually self-limited and can be controlled with the use of Surgifoam (Ethicon, Inc.). Videoangiography with indocyanine green (ICG) is performed intraoperatively to check patency. The sternocleidomastoid muscle is reapproximated, and the wound is closed. 
TABLE 1. Demographic and clinical summary of patients who underwent VA transposition

\begin{tabular}{|c|c|c|c|c|c|c|c|c|c|c|c|}
\hline $\begin{array}{l}\text { Case } \\
\text { No. }\end{array}$ & $\begin{array}{l}\text { Age (yrs) } \\
\text { Sex }\end{array}$ & $\mathrm{Sm}$ & AHTN & $\begin{array}{l}\text { ACoag/ } \\
\text { APtl }\end{array}$ & $\begin{array}{l}\text { Previous } \\
\text { MI/TIA }\end{array}$ & $\begin{array}{l}\text { History } \\
\text { of CEA }\end{array}$ & $\begin{array}{l}\text { Presenting } \\
\text { Symptom(s) }\end{array}$ & Side & $\%$ Stenosis & $\begin{array}{c}\text { Status of } \\
\text { Contralat VA }\end{array}$ & $\begin{array}{c}\text { Transient } \\
\text { Complication(s) }\end{array}$ \\
\hline 1 & $63, \mathrm{~F}$ & + & + & $+/+$ & $-1+$ & - & TIA & $\mathrm{Lt}$ & $70-80$ & $<50 \%$ stenosis & \\
\hline $2^{*}$ & $81, \mathrm{~F}$ & - & + & $+/+$ & $+/+$ & + (bilat) & TIA & $\mathrm{Rt}$ & $80-90$ & Occluded & \\
\hline 3 & $70, \mathrm{M}$ & - & + & $+/+$ & $-1+$ & - & Gait imbalance & $\mathrm{Lt}$ & 60 & $<50 \%$ stenosis & RLN injury (T) \\
\hline 4 & $70, \mathrm{M}$ & + & - & $-1-$ & $-1+$ & - & PCA CVA & Rt & $>90$ & $>90 \%$ stenosis & Horner's syndrome \\
\hline $5 \dagger$ & $62, \mathrm{~F}$ & + & + & $-1+$ & $-1+$ & - & SSS & $\mathrm{Lt}$ & NA & $<50 \%$ stenosis & \\
\hline 6 & $77, \mathrm{M}$ & + & - & $-1-$ & $-1+$ & - & TIA & $\mathrm{Rt}$ & NA & Occluded & \\
\hline $7^{*}$ & $64, \mathrm{M}$ & + & + & $+/+$ & $-1+$ & - & Syncope & $\mathrm{Lt}$ & $70-80$ & NA & Horner's syndrome \\
\hline 8 & $81, \mathrm{M}$ & + & + & $+/+$ & $-1-$ & - & Syncope & $\mathrm{Lt}$ & 60 & NA & \\
\hline 9 & $75, M$ & + & + & $-1+$ & $-1+$ & - & $\mathrm{TIA}$, vertigo & $\mathrm{Lt}$ & $80-90$ & $80-90 \%$ stenosis & Thoracic duct injury \\
\hline 10 & $78, M$ & - & + & $-1-$ & $-1-$ & - & Gait imbalance & $\mathrm{Rt}$ & $60-70$ & Occluded & Horner's syndrome \\
\hline 11 & $75, \mathrm{~F}$ & - & - & $-1+$ & $-1-$ & - & TIA, gait imbalance & $\mathrm{Lt}$ & $>90$ & Occluded & RLN injury $(T)$ \\
\hline 12 & $73, \mathrm{M}$ & - & + & $+/+$ & $-1-$ & - & TIA, vertigo & $\mathrm{Lt}$ & 50 & $<50 \%$ stenosis & \\
\hline 13 & $60, M$ & + & - & $+/+$ & $-1-$ & - & Vertigo & $\mathrm{Lt}$ & $80-90$ & $<50 \%$ stenosis & TIA, slurred speech \\
\hline 14 & $66, M$ & + & + & $+/+$ & $-1+$ & + & CVA & $\mathrm{Rt}$ & $80-90$ & $<50 \%$ stenosis & \\
\hline 15 & $48, M$ & - & - & $+/+$ & $-1+$ & - & $\begin{array}{l}\text { Dysmetria, slurred } \\
\text { speech }\end{array}$ & $\mathrm{Lt}$ & $>90$ & Occluded & $\begin{array}{l}\text { TIA, It leg weak- } \\
\text { ness }\end{array}$ \\
\hline 16 & $73, \mathrm{M}$ & - & - & $-1-$ & $-1-$ & - & TIA, vertigo & $\mathrm{Lt}$ & $>90$ & Occluded & RLN injury \\
\hline 17 & $67, \mathrm{M}$ & - & + & $-1-$ & $-1-$ & - & $\mathrm{SAH}$ & Rt & $60-70$ & Occluded & \\
\hline 18 & $81, M$ & + & + & $+1-$ & $+1-$ & - & TIA, vertigo & $\mathrm{Lt}$ & $70-80$ & Occluded & \\
\hline 19 & $57, \mathrm{M}$ & + & + & $+/+$ & $-1-$ & - & TIA, vertigo & $\mathrm{Lt}$ & $70-80$ & Occluded & Horner's syndrome \\
\hline 20 & $61, \mathrm{~F}$ & - & + & $+/+$ & $-1+$ & - & Vertigo & $\mathrm{Rt}$ & 50 & Occluded & \\
\hline 21 & $67, M$ & + & + & $-1+$ & $-1+$ & + (stent) & CVA & $\mathrm{Lt}$ & $>90$ & Occluded & \\
\hline 22 & $60, M$ & + & + & $+/+$ & $-1+$ & - & CVA & $\mathrm{Lt}$ & $>90$ & Occluded & \\
\hline
\end{tabular}

ACoag = anticoagulation medication; AHTN = antihypertensive medication; APtl = antiplatelet medication; CEA = carotid endarterectomy; MI = myocardial infarction; NA = not applicable; PCA = posterior cerebral artery; RLN = recurrent laryngeal nerve; SAH = subarachnoid hemorrhage; Sm = history of smoking; SSS = subclavian steal syndrome; $\mathrm{T}$ = temporary; - = negative; + = positive .

* Patient received previous stenting/angioplasty treatment.

$\dagger$ Patient experienced restenosis 3 months after surgery and underwent stent placement and angioplasty.

All patients in this study were treated using this technique. The patients were all on aspirin therapy.

\section{Results \\ Patient Characteristics}

The clinical parameters of the patients included in this study can be found in Table 1 . Of the 22 patients in the study, 12 had a significant history of tobacco use, 2 had no documentation of smoking history, and the remaining 8 were nonsmokers. Sixteen patients were hypertensive and were actively being treated with antihypertensive medications. Six patients had no documented history of hypertension. Eleven patients were actively treated for hyperlipidemia, and 17 patients were on antiplatelet or anticoagulation therapy (12 patients on antiplatelet and anticoagulation therapy, 4 on antiplatelet therapy only, and 1 on anticoagulation therapy only). Two patients had a history of myocardial infarction, and 3 patients had undergone carotid endarterectomy for anterior circulation ischemia. Thirteen patients presented with a history of cerebrovascular accident (CVA) or transient ischemic attack (TIA), 1 patient presented with subarachnoid hemorrhage, and the remainder presented with symptoms suggestive of vertebrobasilar insufficiency. Two patients had previously undergone stenting and angioplasty procedures of the affected side without improvement of symptoms. The left side was more commonly involved ( 15 on the left vs 7 on the right). In a majority of the patients $(n=18)$, the contralateral VA was noted to exhibit mild to severe stenosis.

\section{Morbidity and Mortality}

There were no cases of perioperative death in this series. We identified 3 cases of recurrent laryngeal nerve palsy, 1 of which had not resolved at latest follow-up, 4 cases of temporary Horner's syndrome, 2 cases of postoperative TIA, and 1 case of thoracic duct injury associated with a left-sided approach (Table 2).

\section{Follow-Up}

Clinical follow-up information was available for $20 \mathrm{pa}-$ tients. At a mean clinical follow-up of 4.4 months (range postoperatively to 17 months), all patients had resolution or improvement of their presenting symptoms (Figs. 1 and 2). At a mean angiographic follow-up of 8.8 months, clinically significant restenosis was evident in a single case. This patient was treated with stenting 3 months after the microsurgical revascularization. 


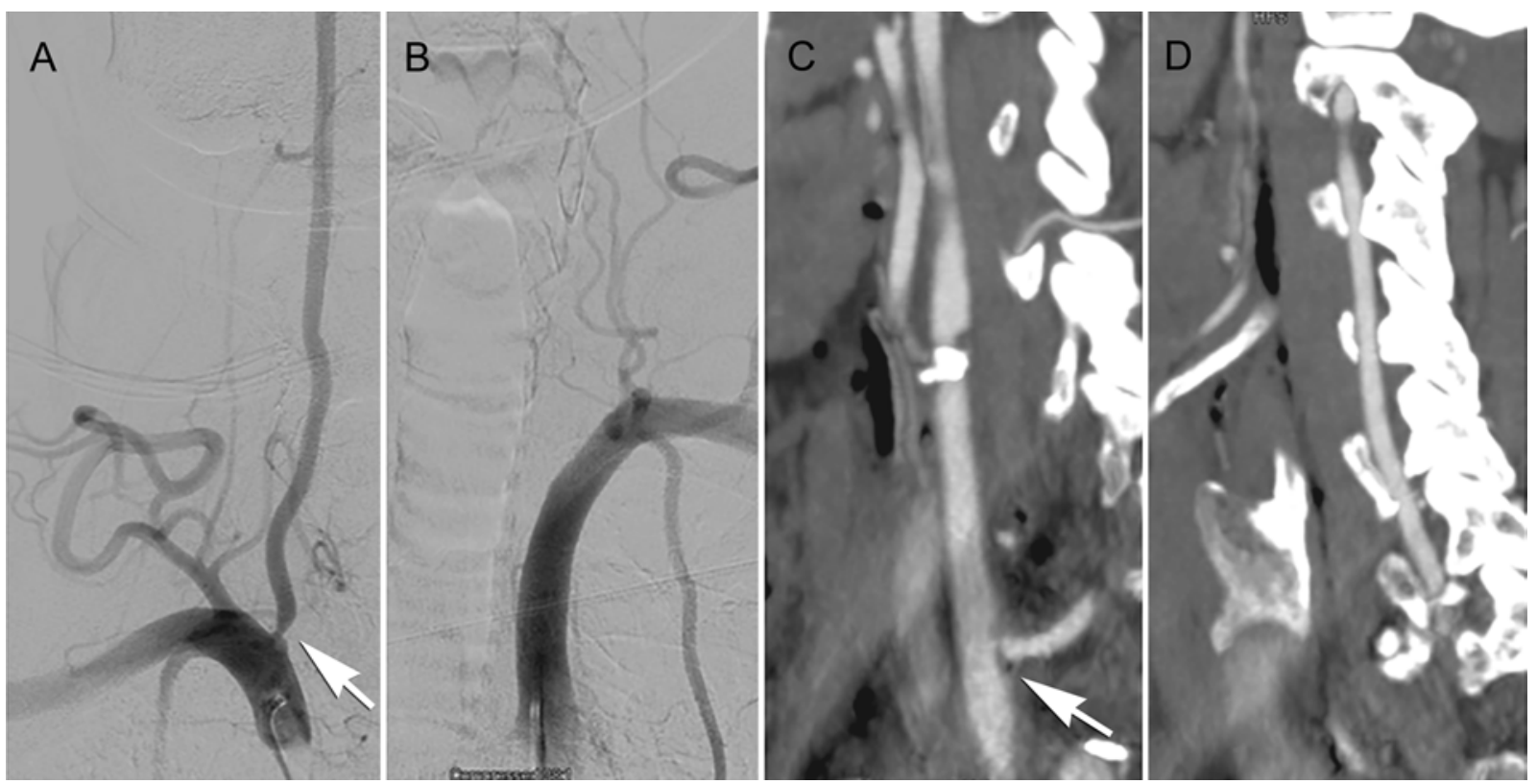

FIG. 1. A 67-year-old man with acute subarachnoid hemorrhage with negative results on 2 cerebral angiography studies was found to have moderate to severe stenosis (arrow) of the right VA (A) and complete occlusion of the left VA (B). The patient underwent a right VA-CCA transposition (C and D). At 6-month follow-up examination, CTA (C) demonstrated adequate patency and flow (arrow) of the VA-CCA anastomosis.

\section{Discussion}

Previous reports of microsurgical revascularization of the proximal VA consisted of small cohorts of patients treated with a diverse array of revascularization techniques. ${ }^{2,5,9,10,14,25}$ These techniques included endarterectomy of the proximal VA and subclavian artery, ${ }^{5} \mathrm{VA}-\mathrm{CCA}$ transposition, ${ }^{14}$ and placement of interposition grafts. ${ }^{9}$ These series consisted of relatively short-term follow-up and focused on immediate symptom improvement (Table
3). Still, there are no randomized data on the benefit of revascularization of the proximal VA for stroke prevention. However, cervical carotid trials ${ }^{11,12,23}$ and case series support microsurgical or endovascular treatment., ${ }^{1,2,9,10,17,25}$ The goal for either treatment is successful resolution of the patients' symptoms and an angiographic result $(<$ $50 \%$ residual stenosis) without neurological or procedurerelated complications. ${ }^{14}$ The success rates of both modalities are similar, ranging from $93 \%$ to $98 \%{ }^{1,2,6,9,16,25,26,28}$
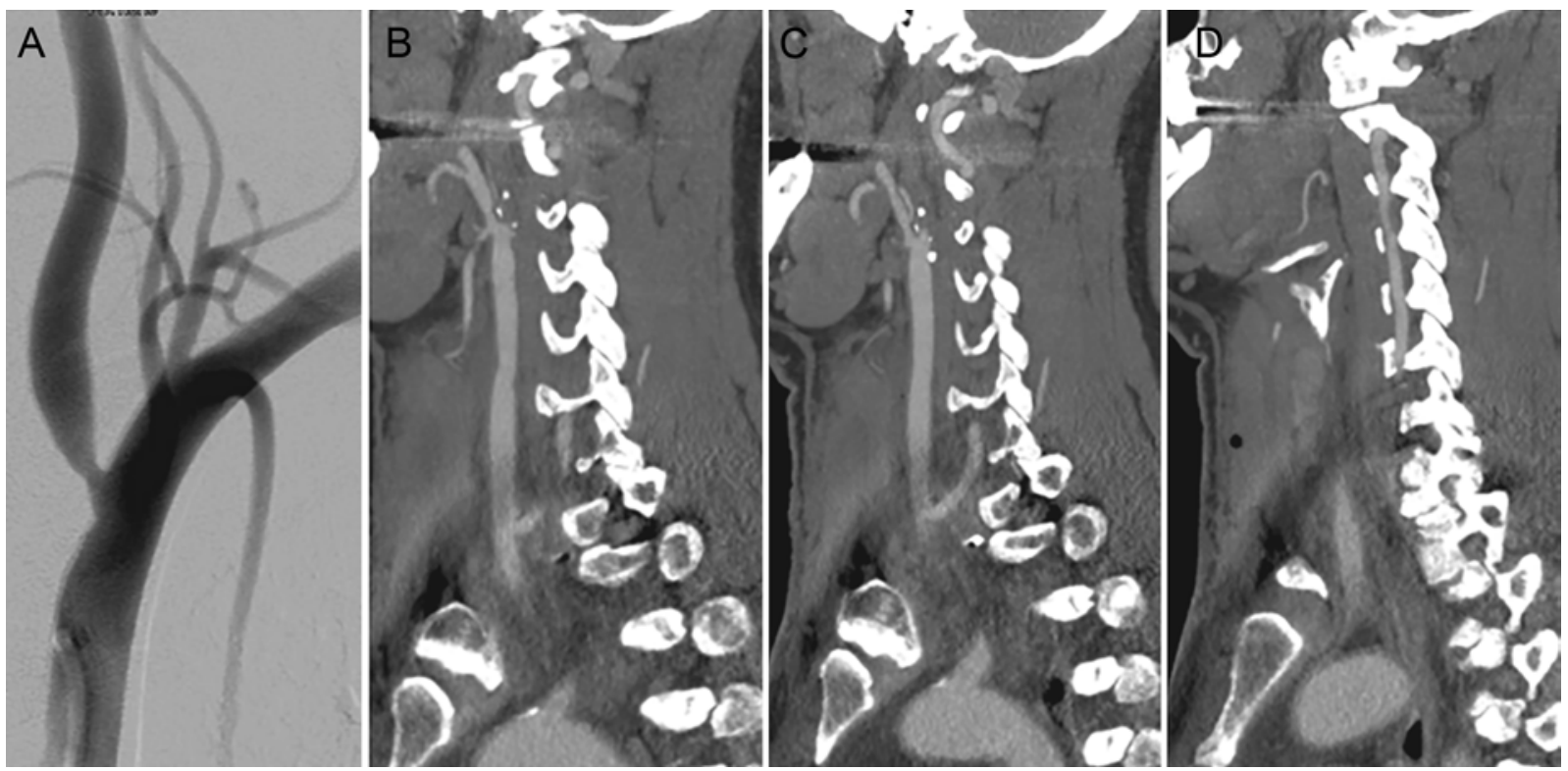

FIG. 2. A 58-year-old man presented with vertigo, dizziness, and brainstem stroke. Cerebral angiography demonstrated a complete occlusion of the right VA and severe stenosis of the left VA (A and B). The patient underwent a left VA-CCA transposition. One-month postoperative CTA of the neck ( $C$ and $D$ ) showed adequate patency and flow through the anastomosis. 
TABLE 2. Procedure-related complications

\begin{tabular}{lcc}
\hline \multirow{2}{*}{ Complication } & \multicolumn{2}{c}{ No. of Cases } \\
\cline { 2 - 3 } & Temporary & Permanent \\
\hline Wound hematoma & 0 & 0 \\
\hline Recurrent laryngeal nerve injury & 2 & 1 \\
\hline Intraop thoracic duct injury & 1 & 0 \\
\hline Chylothorax & 0 & 0 \\
\hline Horner's syndrome & 4 & 0 \\
\hline Postop TIA & 2 & 0 \\
\hline
\end{tabular}

Here we have presented a series of 22 consecutively treated patients with medically refractory posterior circulation ischemia who underwent VA-CCA transposition. A majority of the patients in this series had an extensive history of tobacco use and hypertension. Seventy-five percent of the patients were treated aggressively with antiplatelet therapy, anticoagulation therapy, or both therapies. In $50 \%$ of the cases, the patients presented with a completely occluded contralateral VA, and a majority of the patients presented after suffering a CVA or TIA, in accordance with previous literature. For all the patients treated microsurgically, we identified resolution or improvement of their symptoms and adequate angiographic results. To our knowledge, this population represents the largest cohort of patients treated with this strategy to date.

When selecting the method of choice for revascularization of the proximal VA, the durability of the treatment becomes crucial. Albuquerque et al. ${ }^{1}$ found restenosis in $43.3 \%$ of patients who underwent angioplasty and stenting for revascularization of the proximal VA. Similar results have consistently been reported in other studies.1,19,20,26 In the Stenting of Symptomatic Atherosclerotic Lesions in the Vertebral or Intracranial Arteries trial, $43 \%$ of the patients who received treatment for extracranial VA stenosis and had 6 months of follow-up had evidence of in-stent stenosis. Half of them had a complete vessel occlusion. ${ }^{26}$ Recently, Li et al. ${ }^{18}$ demonstrated the efficacy of balloon-assisted angioplasty and self-expanding stents in 32 patients with symptomatic VA ostium stenosis. The mean extent of stenosis before and after stenting declined from $76.4 \%$ to $11.4 \%$, and only 1 patient $(3.1 \%$ ) developed asymptomatic restenosis at a mean angiographic followup of 12.5 months. Drug-eluting stents can reduce restenosis rates by inhibiting neointimal hyperplasia, but the stent fracture rate is significantly high?

The durability of microsurgical revascularization has been described extensively. ${ }^{9,10,14,16,17,19}$ Hanel et al. ${ }^{14}$ reported that $7 \%$ of patients developed new or recurrent vertebrobasilar symptoms after surgery (mean follow-up 29 months). Their angiographic results showed only 1 case of recurrent stenosis among those patients who underwent follow-up imaging. Berguer et al. ${ }^{2}$ reported a $71 \%$ 5-year survival rate for patients with extracranial VA disease undergoing microsurgical revascularization. A majority of the patients who died did so as a result of cardiac disease. Of those patients with 5 years of follow-up after microsurgical intervention, 97\% remained stroke free. ${ }^{2}$ In the present series, in a mean follow-up period of 8.8 months,
1 patient had restenosis 3 months after the microvascular procedure and required endovascular stenting.

\section{Temporary and Permanent Complications}

Complications of endovascular treatment for VA stenosis are variable. Parkhutik et al. ${ }^{24}$ reported a neurological complication rate of $3.4 \%$, with 1 immediate vertebral TIA and 2 other strokes during a mean 32-month follow-up period. Fiorella et al. ${ }^{13}$ reported periprocedural neurological morbidity and mortality rates of $26.1 \%$, including 10 clinically evident strokes, in patients with vertebrobasilar atheromatous disease undergoing endovascular treatment. Mohammadian et al. ${ }^{22}$ recently presented their experience in using angioplasty and stenting to treat symptomatic VA stenosis and found periprocedural and follow-up complication rates of $7.2 \%$ and $6.3 \%$, respectively. Microsurgical revascularization of the VA has inherent risks of complication from soft-tissue manipulation, such as wound infection or hematoma, laryngeal nerve injury, thrombosis, lymphatic injury, Horner's syndrome, and stroke. In a large series that included 218 proximal VA transpositions, Berguer et al. ${ }^{2}$ found a mortality rate of $0.6 \%$ and a perioperative stroke rate of $1.9 \%$. Their patency rate at 5 years was $80 \%$. Hanel et al..$^{14}$ reported incidence rates of $48.3 \%$ for transient and $7.4 \%$ for permanent neurological deficits. Only 2 patients had new symptoms related to vertebrobasilar insufficiency, and 1 patient had a new distal vertebral stenosis 17 years after surgery.

In the current series, we did not identify any cases of perioperative death associated with this treatment strategy, but we did identify an array of temporary complications and 1 permanent complication. We noted recurrent laryngeal nerve palsies in 3 patients. This complication was temporary in all of them except for 1 at last followup. There was 1 case of a thoracic duct injury associated with a left-sided approach that was identified intraoperatively and treated without sequelae. We identified 4 cases of temporary Horner's syndrome and 2 cases of perioperative TIA. Postoperative CVAs have been reported in association with both microsurgical and endovascular treatment of the proximal VA and seem to be associated with manipulation of the atherosclerotic burden within the vessel. Anatomical knowledge and gentle tissue manipulation are the bases for avoiding complications.

\section{Conclusions}

Despite advancements in medical therapy, a subset of patients with vertebrobasilar insufficiency remain candidates for microsurgical revascularization of the posterior circulation. Although endovascular management has contributed to a decline in the surgical treatment of vertebrobasilar insufficiency, the long-term outcomes for patients subjected to this regimen remain limited, and the rates of restenosis, even with drug-eluting stents, remain high. In experienced hands, microsurgical revascularization of the proximal VA using VA-CCA transposition is a safe and effective treatment for medically refractory vertebrobasilar insufficiency. 


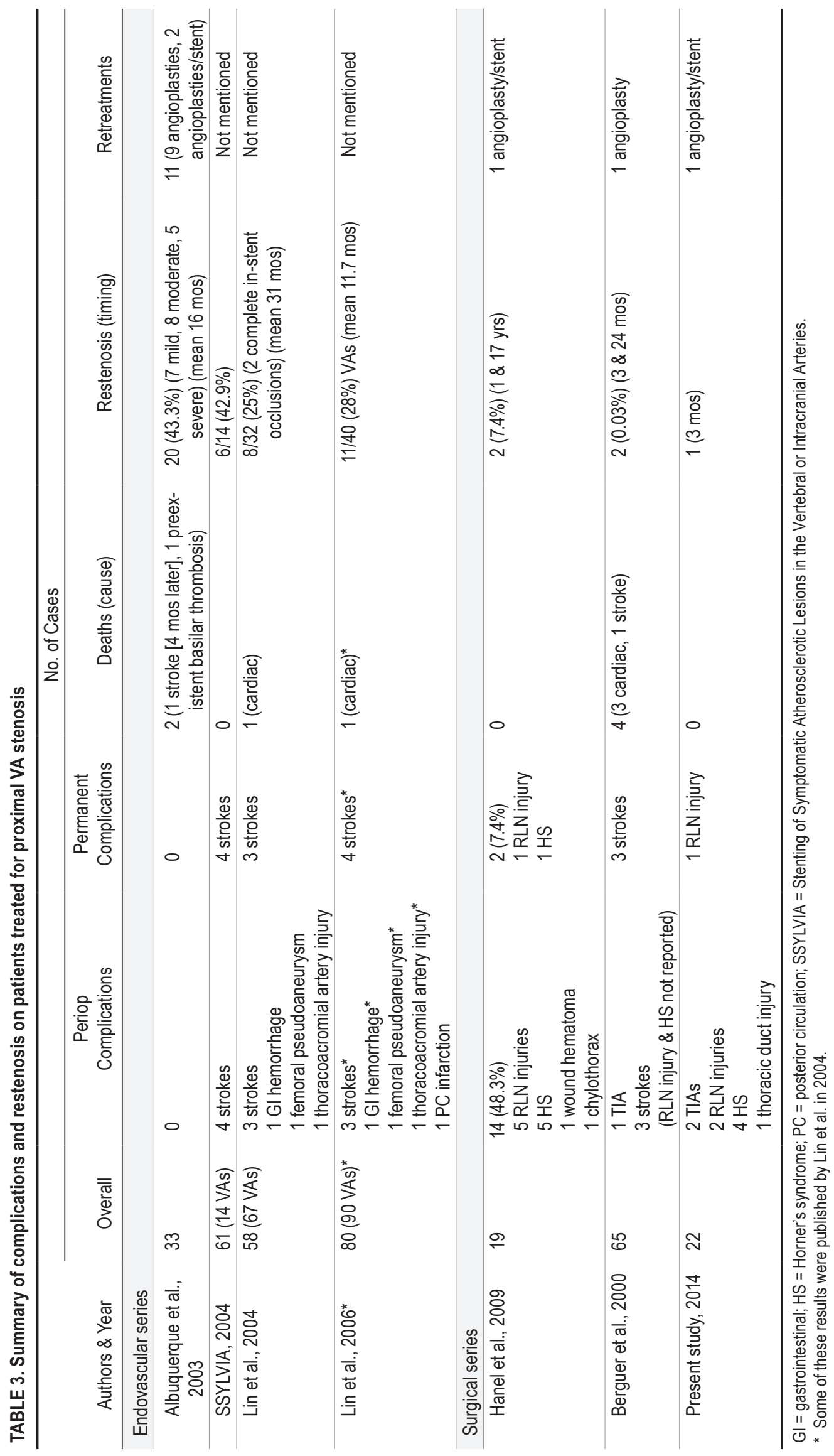




\section{References}

1. Albuquerque FC, Fiorella D, Han P, Spetzler RF, McDougall CG: A reappraisal of angioplasty and stenting for the treatment of vertebral origin stenosis. Neurosurgery 53:607-616, 2003

2. Berguer R, Flynn LM, Kline RA, Caplan L: Surgical reconstruction of the extracranial vertebral artery: management and outcome. J Vasc Surg 31:9-18, 2000

3. Bogousslavsky J, Van Melle G, Regli F: The Lausanne Stroke Registry: analysis of 1,000 consecutive patients with first stroke. Stroke 19:1083-1092, 1988

4. Caplan LR, Wityk RJ, Glass TA, Tapia J, Pazdera L, Chang HM, et al: New England Medical Center Posterior Circulation registry. Ann Neurol 56:389-398, 2004

5. Cate WR Jr, Scott HW Jr: Cerebral ischemia of central origin: relief by subclavian-vertebral artery thromboendarterectomy. Surgery 45:19-31, 1959

6. Chastain HD II, Campbell MS, Iyer S, Roubin GS, Vitek J, Mathur A, et al: Extracranial vertebral artery stent placement: in-hospital and follow-up results. J Neurosurg 91:547-552, 1999

7. Chen X, Huang Q, Hong B, Zhang Y, Xu Y, Liu J: Drugeluting stent for the treatment of symptomatic vertebral origin stenosis: long-term results. J Clin Neurosci 18:47-51, 2011

8. Coward LJ, McCabe DJ, Ederle J, Featherstone RL, Clifton A, Brown MM: Long-term outcome after angioplasty and stenting for symptomatic vertebral artery stenosis compared with medical treatment in the Carotid And Vertebral Artery Transluminal Angioplasty Study (CAVATAS): a randomized trial. Stroke 38:1526-1530, 2007

9. Diaz FG, Ausman JI, de los Reyes RA, Pearce J, Shrontz C, Pak H, et al: Surgical reconstruction of the proximal vertebral artery. J Neurosurg 61:874-881, 1984

10. Edwards WH, Edwards WH Jr: Vertebral-carotid transposition. Semin Vasc Surg 13:70-73, 2000

11. European Carotid Surgery Trialists' Collaborative Group: MRC European Carotid Surgery Trial: interim results for symptomatic patients with severe (70-99\%) or with mild (029\%) carotid stenosis. Lancet 337:1235-1243, 1991

12. Executive Committee for the Asymptomatic Carotid Atherosclerosis Study: Endarterectomy for asymptomatic carotid artery stenosis. JAMA 273:1421-1428, 1995

13. Fiorella D, Chow MM, Anderson M, Woo H, Rasmussen PA, Masaryk TJ: A 7-year experience with balloon-mounted coronary stents for the treatment of symptomatic vertebrobasilar intracranial atheromatous disease. Neurosurgery 61:236-243, 2007

14. Hanel RA, Brasiliense LB, Spetzler RF: Microsurgical revascularization of proximal vertebral artery: a single-center, single-operator analysis. Neurosurgery 64:1043-1051, 2009

15. Hass WK, Fields WS, North RR, Kircheff II, Chase NE, Bauer RB: Joint study of extracranial arterial occlusion. II. Arteriography, techniques, sites, and complications. JAMA 203:961-968, 1968

16. Imparato AM: Vertebral arterial reconstruction: a nineteenyear experience. J Vasc Surg 2:626-634, 1985

17. Koskas F, Kieffer E, Rancurel G, Bahnini A, Ruotolo C, Illuminati G: Direct transposition of the distal cervical vertebral artery into the internal carotid artery. Ann Vasc Surg 9:515-524, 1995

18. Li Z, Zhang Y, Hong B, Deng B, Xu Y, Zhao W, et al: Stenting of symptomatic vertebral artery ostium stenosis with selfexpanding stents. J Clin Neurosci 21:274-277, 2014

19. Lin YH, Juang JM, Jeng JS, Yip PK, Kao HL: Symptomatic ostial vertebral artery stenosis treated with tubular coronary stents: clinical results and restenosis analysis. J Endovasc Ther 11:719-726, 2004

20. Lin YH, Liu YC, Tseng WY, Juang JM, Hung CS, Lin JW, et al: The impact of lesion length on angiographic restenosis after vertebral artery origin stenting. Eur J Vasc Endovasc Surg 32:379-385, 2006

21. Mazighi M, Labreuche J, Gongora-Rivera F, Duyckaerts C, Hauw JJ, Amarenco P: Autopsy prevalence of proximal extracranial atherosclerosis in patients with fatal stroke. Stroke 40:713-718, 2009

22. Mohammadian R, Sharifipour E, Mansourizadeh R, Sohrabi B, Nayebi AR, Haririan S, et al: Angioplasty and stenting of symptomatic vertebral artery stenosis. Clinical and angiographic follow-up of 206 cases from Northwest Iran. Neuroradiol J 26:454-463, 2013

23. North American Symptomatic Carotid Endarterectomy Trial Collaborators: Beneficial effect of carotid endarterectomy in symptomatic patients with high-grade carotid stenosis. N Engl J Med 325:445-453, 1991

24. Parkhutik V, Lago A, Tembl JI, Aparici F, Vazquez V, Mainar E: Angioplasty and stenting of symptomatic and asymptomatic vertebral artery stenosis: to treat or not to treat. Eur J Neurol 17:267-272, 2010

25. Spetzler RF, Hadley MN, Martin NA, Hopkins LN, Carter LP, Budny J: Vertebrobasilar insufficiency. Part 1: Microsurgical treatment of extracranial vertebrobasilar disease. J Neurosurg 66:648-661, 1987

26. SSYLVIA Study Investigators: Stenting of Symptomatic Atherosclerotic Lesions in the Vertebral or Intracranial Arteries (SSYLVIA): study results. Stroke 35:1388-1392, 2004

27. Stayman AN, Nogueira RG, Gupta R: A systematic review of stenting and angioplasty of symptomatic extracranial vertebral artery stenosis. Stroke 42:2212-2216, 2011

28. Wehman JC, Hanel RA, Guidot CA, Guterman LR, Hopkins LN: Atherosclerotic occlusive extracranial vertebral artery disease: indications for intervention, endovascular techniques, short-term and long-term results. J Interv Cardiol 17:219232, 2004

\section{Author Contributions}

Conception and design: Rangel-Castilla, Kalani, Cronk, Russin. Acquisition of data: Rangel-Castilla, Kalani. Analysis and interpretation of data: Rangel-Castilla, Kalani, Russin. Drafting the article: Rangel-Castilla, Kalani, Cronk, Zabramski, Russin. Critically revising the article: Spetzler, Zabramski. Reviewed submitted version of manuscript: Spetzler, Zabramski. Statistical analysis: Rangel-Castilla, Kalani, Russin. Administrative/techni$\mathrm{cal} /$ material support: Cronk, Russin. Study supervision: Spetzler, Zabramski.

\section{Supplemental Information \\ Videos}

Video 1, Media Player. http://mfile.akamai.com/21490/wmv/ digitalwbc.download.akamai.com/21492/wm.digitalsource-naregional/jns14-194_video_1.asx.

Video 1, Quicktime. http://mfile.akamai.com/21488/mov/ digitalwbc.download.akamai.com/21492/qt.digitalsource-global/ jns14-194_video_1.mov.

Video 2, Media Player. http://mfile.akamai.com/21490/wmv/ digitalwbc.download.akamai.com/21492/wm.digitalsource-naregional/jns14-194_video_2.asx.

Video 2, Quicktime. http://mfile.akamai.com/21488/mov/ digitalwbc.download.akamai.com/21492/qt.digitalsource-global/ jns14-194_video_2.mov.

\section{Correspondence}

Robert F. Spetzler, Neuroscience Publications, Barrow Neurological Institute, St. Joseph's Hospital and Medical Center, 350 W. Thomas Rd., Phoenix, AZ 85013. email: neuropub@ dignityhealth.org. 